\title{
Rediscussing centres and peripheries: communication lenses on migration. ECREA 2018 special panel report
}

\author{
Sara Greco*, USI - Università della Svizzera italiana \\ Jolanta Drzewiecka, USI - Università della Svizzera italiana \\ *Corresponding author: sara.greco@usi.ch
}

\begin{abstract}
The ECREA 2018 special panel "Rediscussing centers and peripheries: communication lenses on migration" was held at the ECREA conference on 2 November 2018, in the beautiful venue of a frescoed room at Villa Ciani. The panel was co-organized by the two authors of this report, Jolanta Drzewiecka and Sara Greco, both from USI Università della Svizzera italiana. As the organizers, we provide a brief report of the rationale, aims and expectations that we had for this panel. We then include a discussion on how the panel exceeded our expectations by encouraging profoundly critical communication lenses on migration.
\end{abstract}

\section{Note}

Invited report for the Thematic Section on ECREA 2018 devoted to the $7^{\text {th }}$ European Communication Conference of the European Communication and Research Association (ECREA), held in Lugano from October $31^{\text {st }}$ to November $3^{\text {rd }}, 2018$.

\section{A panel on migration within the ECREA 2018 conference: aims and rationale}

The topic of ECREA 2018 was "Centers and peripheries: Communication, research, translation". Etymologically, periphery is a circumference, which encloses the center; and all the points on a circumference, famously, have the same distance from the center. But when you turn these geometrical concepts into geographical metaphors, as we are used to do in everyday language, you immediately understand that the reality of communication and migration is much more complex. For one, migration is certainly poly-centric - there is no single endpoint of migration trajectories, which are directed towards different 'target countries' and often include different steps. Besides, as we may say, 'not all peripheries are equal', i.e. physically or symbolically equidistant from the center(s). Moreover, do migration centers and peripheries coincide with centers and peripheries of communication, or how are they combined? Are migrants trajectories combined with communication flows? And, if yes, do we see these flows, or are we often communicating about migrants and refugees, selectively representing some specific trajectories and stories that concern 'us' more directly, and without leaving 'them' enough space to voice their views?

Our panel intended to open these and many more questions, presenting us with critical perspectives on migration, and combining different methodologies and approaches. The panel was therefore organized with a clear critical focus and with the intention of (re)discussing methods, approaches and starting points that might seem obvious prima facie, but are not. For this reason, scholars who adopt different methodologies and are based in different geographical areas were invited: when you talk about international migration, the local and the global are necessarily interconnected, and it is important to see different linguistic, cultural and geographical perspectives on communication in this field. 


\section{Contents and participants}

The panel included five presentations, which we will briefly present in this section. Notably, the first three papers nicely fit together into a thematic block that proposed a critical view on research methods to address the phenomenon of migration, advocating the importance of including migrants' voices into the picture, by looking for platforms and media that represent their communication or even launching activist initiatives. Kaarina Nikunen (University of Tampere), together with Matti Nelimarkka, Markus Ojala, Mervi Pantti, Juho Pääkkönen and Reeta Pöyhtäri presented a paper titled: "What big data hides: methodological challenges of researching migration, experience and voice". They advocated a critical view on big data relative to communication about migration, trying to focus on how participatory aspects might remain hidden if we do not pay special attention to them. While big data certainly offer a new source of information on the prominent themes and topics of the discussion on migration, the authors observed that they often hide the voices of the marginalized, namely, voices of migrants and refugees. Therefore, this contribution advocated a critical assessment of the methods of research on migration, striving to integrate what the authors called 'counter-voices' that emerge on social media, blogs and activist media, such as the 'Migrant Tales' activist blog and campaigns.

Focused on a specific public diplomacy initiative led by the US Embassy in Athens and based on a 'hackaton', the paper by Betty Tsakarestou (Panteion University of Social and Political Sciences, Athens, Greece) and her colleagues Ammina Kothari and Lida Tsene considered interventions that are entrepreneurship-driven and aim at establishing partnerships. This paper, titled "Hack the Camp": An entrepreneurial public diplomacy tri-sector partnership initiative to address refugee crisis in Greece', discussed how this type of initiatives - which, in the authors' words, may become 'triggering events' for partnership - might be connected to a re- search approach that, in a bottom-up way, considers refugees as key stakeholders and, therefore, also producers of communication.

The contribution by Koen Leurs (Utrecht University, The Netherlands), co-authored by Ena Omerović, Hemmo Bruinenberg and Sanne Sprenger ('Critical media literacy through making media: A key to participation for young migrants?') also focused on migrants' communication agency. The authors were reflecting on a media literacy program developed at an 'International Transition Classes' school in The Netherlands, preparing young newcomers between 12 and 18 years to be admitted to 'regular' education in Dutch. The program included raising awareness on dominant visual and verbal messages on migrants or against migrants - and sought to enable young participants to critically position themselves and to 'assert themselves in their own terms'. Once again, while discussing the merits of this initiative, the authors presented their ethnographic research methods, based on a combination of field notes, in-depth and informal interviews, focus groups, student-produced footage and two ethnographic films documenting the experience. Notably, as we might observe, the data deriving from this ethnographic method are multi-authored, with migrants being not only an 'object of' but also an 'agent in' communication studies.

While the first three papers of this panel clearly addressed the problem of what it means to do research on communication and migration taking migrants' voices into account, the last two papers were advocating a critical view of migrants' representations on mainstream media in different European countries. Arguably, these two papers were complementary to the first three ones: they made the point that current representations of migrants described from an external perspective only - are insufficient, or even misleading. "Goods to be delivered" and "Floods to be contained". The European refugee crisis in the Spanish press', by Carlota M. Moragas Fernández (Universitat Rovira i Virgili, Tarragona, Spain) and her colleague Marta 
Montagut Calvo, considered metaphors as lexical choices to convey ideology, starting from the works by Wodak (e.g. Wodak 2006) and Critical Metaphor Analysis (Charteris-Black 2004). They focused on metaphorical expressions employed by a selection of Spanish mainstream newspapers: El País, La Vanguardia and El Mundo. In particular, the authors reflected on the events relative to the summer of 2015, unveiling recurring metaphors related to the journey (movement), to containers (with Europe becoming a - too full? - container), water and fluids, with the clearly dehumanizing representations of 'waves' or 'floods' of people entering the European borders. These metaphors, obviously, call into question not only European representations of migrants but also the identity of Europe and of the European Union as a political process.

In a similar vein, the last paper, presented by Gian-Louis Hernandez (USI Università della Svizzera italiana, Lugano, Switzerland) with Jolanta Drzewiecka and Sara Greco ("Fortress Europe" divided: Discourse theoretical and argumentative analysis of the coverage of border closing by European Newspapers'), discussed preliminary findings of a multi-country and multi-language project. This project concerns the representation of borders and discursive struggles on bordering in Europe (see Cisneros 2011), taking into account how a selection of mainstream media from Germany (Frankfurter Allgemeine Zeitung and Süddeutsche Zeitung), Italy (la Repubblica and Corriere della Sera), Poland (Gazeta Wyborcza and Rzeczpospolita) and the UK (The Times UK and The Guardian) represented migrants and borders in the summer of 2015. This project combines discourse theoretical and argumentation-based approaches, trying to unveil practices of moralization (of bordering, border closing and similar practices activated by countries within the EU) and related instances of politicization of the migrant crisis. Interestingly, looking at the same phenomenon during the same time span from the perspective of different EU countries shows how centres and peripheries are part of a discursive con- struction that can vary significantly. Migrants' trajectories, numbers, internal and external EU borders and relations between countries are rediscussed in different ways depending on the country and its relationship to the EU project.

\section{Outcomes and reflections}

Clearly emerging from the papers and the lively discussion with the participants and attendees in this panel was a widespread awareness of the fact that 'communication on migration' or 'communication and migration' is, before anything else, a research object that needs to be clarified. It would be a mistake to think that communication flows regarding migrants or even produced by migrants are just 'out there' and the researcher only needs to analyse them. On the contrary, the very process of gathering data, selecting a research method, or a communication platform that contains data, or deciding what to include and what to exclude are all practices that are importantly related to humanizing or dehumanizing practices of migrants and refugees. Not by chance, some authors in the panel discussed the connection between methodology and justice. In this perspective, migrants should leave the status of 'objects of communication' and acquire the status of 'subjects', as human beings and producers of communication. Put differently, to stay with the title of this panel, which contained the phrase 'communication lenses on migration', we need to be aware that we are wearing lenses when we approach this research topic. All five papers, in different ways, clearly made the point that critical reflection on this aspect is needed. And going beyond the boundaries of this specific panel, some critical awareness of the limits of methodology is certainly an aspect that might bear relevance to other communication domains.

In the framework of the Lugano ECREA conference, the combination of research methods and the struggle to hear voices and counter-voices might be seen as a practice of questioning centres and peripheries. In some cases, the research 
methods used in the papers involved some degree of activist initiatives, proposed and/or studied by participants in this panel. We had extremely inspiring descriptions of case studies and initiatives. We also had a very specific focus on some crucial events or moments in time, such as the summer of 2015. This was a time in which migration and communication met: refugees made headlines for weeks, often with controversy on their trajectories, starting points and endpoints, on Europe's capacity and responsibility to welcome them, on country-specific and European identities, and so on. A question that might or should remain open for future research is how the important work done by participants to this panel through diverse initiatives and case studies, as well as through in-depth analyses of specific events like the summer of 2015, could be generalized and made into a more systemic methodological approach. Moreover, further research needs to integrate new methods and the use of more 'traditional' datasets (mainstream media, big data etc.). This panel was an occasion to start a dialogue on these important questions for methodologies in the field of communication and discourse studies.

\section{Panel overview}

\author{
Panel title \\ Reconfiguring centres and peripheries: \\ Communication lenses on migration \\ Panel organizers \\ Jolanta Drzewiecka, Sara Greco (USI Uni- \\ versità della Svizzera italiana) \\ Date and location \\ Friday, $2^{\text {nd }}$ November, 14:30-16:00 Villa \\ Ciani, Room 015
}

What big data hides: Methodological challenges of researching migration, experience and voice.

Nikunen, K. (University of Tampere, Faculty of Communication Sciences, Tampere, Finland)
Nelimarkka, M. (Aalto University, Institute for Information Technology HIIT, Helsinki, Finland)

Ojala, M. (University of Helsinki, Department of Social Research, Media and Communication Studies, Helsinki, Finland)

Pantti, M. (University of Helsinki, Department of Social Research, Media and Communication Studies, Helsinki, Finland)

Pääkkönen, J. (University of Helsinki, Department of Sociology, Helsinki, Finland)

Pöyhtäri, R. (University of Tampere, Department of Journalism and Mass Communication, Tampere, Finland)

"Hack the Camp": An entrepreneurial public diplomacy tri-sector partnership initiative to address refugee crisis in Greece. A "Hacking" method and process in engaging citizens and refugees as co-creative entrepreneurs and solution makers.

Tsakarestou, B. (Panteion University of Social and Political Sciences, Department of Communication, Media and Culture, Athens, Greece)

Kothari, A. (School of Communication, Rochester Institute of Technology, Rochester, USA)

Tsene, L. (Athens, Greece)

Critical media literacy through making media: A key to participation for young migrants?

Leurs, K. (Utrecht University, Institute for Cultural Inquiry (ICON), Utrecht, Netherlands)

Omerovic , E. (Utrecht University, Utrecht, Netherlands)

Bruinenberg, H. (Utrecht University, Utrecht, Netherlands)

Sprenger, S. (Utrecht University, Institute for Cultural Inquiry (ICON), Utrecht, Netherlands)

Goods to be delivered" and "Floods to be contained". The European refugee crisis in the Spanish press Moragas-, C.M. (Rovira $i$ Virgili University, Department of Communication Studies, Tarragona, Spain).

Montagut Calvo, M. (Rovira i Virgili University, Department of Communication Studies, Tarragona, Spain) 
"Fortress Europe" divided: Discourse theoretical and argumentative analysis of the coverage of border closing by European newspapers.

Hernandez, G.L. (USI Universita della Svizzera italiana, Institute for Public Communication (ICP), Lugano, Switzerland)

Drzewiecka, J. (USI Universita della Svizzera italiana, Institute for Public Communication (ICP), Lugano, Switzerland)

Greco, S. (USI Universita della Svizzera italiana, Institute of Argumentation, Linguistics and Semiotics (IALS), Lugano, Switzerland)

\section{References}

Charteris-Black, J. (2004). Corpus approaches to critical metaphor analysis. New York: Palgrave.

Cisneros, J. D. (2011). (Re)bordering the civic imaginary: Rhetoric, hybridity, and citizenship in La Gran Marcha. Quarterly Journal of Speech, 97(1), 26-49.

Wodak, R. (2006). Mediation between discourse and society: assessing cognitive approaches in CDA. Discourse Studies, 8(1), 179-190. 
